\title{
Um Jogo Sério de Aventura sobre a Interação com os Índios Xokleng durante a Colonização de Ibirama/SC
}

\author{
Adilson Vahldick, Euler Giachini \\ Universidade do Estado de Santa Catarina (Udesc Alto Vale) \\ adilson.vahdick@udesc.br, eulergiachini@gmail.com
}

Resumo. A disciplina de História objetiva equipar os alunos com capacidades de refletir sobre eventos passados para que entendam o contexto presente e não repitam os mesmos erros. O jogo, descrito nesse artigo, permite que o aluno vivencie as três primeiras décadas da colonização de Ibirama. Duas turmas $(n=35)$ foram usadas para avaliar a abordagem no uso do jogo. Para uma das turmas foi lecionada uma aula sobre o assunto antes do jogo. Os testes estatísticos apresentaram uma melhora significativa de ambas as turmas após a experiência de jogo. Ainda, comparando o conhecimento adquirido entre os alunos que jogaram e os que tiveram aula, os primeiros apresentaram melhor desempenho. Isso apresenta uma abordagem eficiente de aprender fatos, datas e vultos para que o professor consiga atingir o objetivo principal das aulas de História.

Palavras-chaves. História local. Jogos sérios. Colonização de Ibirama. Índios Xokleng.

\section{A Serious Adventure Game about Xokleng Indians during the Colonization of Ibirama/SC}

\begin{abstract}
The History course aims to equip students with the ability to reflect on past events so that they understand the present context and do not repeat the same mistakes. The game, described in this article, allows the student to experience the first three decades of Ibirama's colonization. Two classes $(n=35)$ were used to assess the approach to using the game. For one of the classes, a class was taught on the subject before the game. Statistical tests showed a significant improvement in both classes after the game experience. Still, comparing the knowledge acquired between the students who played and those who had classes, the former showed better performance. This presents an efficient approach to learn facts, dates and figures so that the teacher can achieve the main objective of History classes.
\end{abstract}

Keywords. Local history. Serious games. Colonization of Ibirama. Xokleng Indians.

\section{Introdução}

Com a implantação dos Parâmetros Curriculares Nacionais (PCN) em 1997, a disciplina de Estudos Sociais foi dividida em Geografia e História, "reforçando o caráter formativo da História na constituição da identidade, da cidadania, do reconhecimento do outro, do respeito à pluralidade cultural e da defesa do fortalecimento da democracia" (Silva \& Fonseca, 2010). Contudo, conforme descreve Caimi (2006) como propósito da escola tradicional, ao ensinar História, está voltado para a aquisição cumulativa de informações, bem como a ordenação mecânica de fatos em causas e consequências, o que desconsidera e desvaloriza as experiências cotidianas e práticas sociais dos alunos. É difícil para os alunos fazerem algum sentido as informações que não fazem parte do seu cotidiano seja por questões sociais, culturais ou econômicas (Seffner, 2018).

O uso de recursos lúdicos nas aulas de História não são apenas instrumentos motivadores, mas interferem e conferem significados singulares às noções e os conteúdos que se queiram trabalhar (Andrade, 2007). Para aprender em história depende do aluno se deslocar no tempo, "mergulhar" num tempo isolado e limitado, vivenciando e tomando contato com as decisões nas condições que haviam disponíveis naquele tempo (Pereira \& V. $18 \mathrm{~N}^{\mathrm{v}} 1$, julho, 2020 RENU'IE DOI: 
Giacomoni, 2018). O potencial dos jogos reside na capacidade de cativarem a aprendizagem através da imersão, onde o jogador vive a personagem do jogo, transmitindo-lhe as suas esperanças, valores e medos (Gee, 2003). Ainda, McCall (2016) descreve que as grandes contribuições das simulações e jogos incluem sua capacidade de imergir os jogadores em um contexto histórico atenuando a visão retrospectiva que atormenta as interpretações históricas e oferecendo modelos explicativos defensáveis dos sistemas históricos.

Diante da perspectiva de fornecer um recurso lúdico que auxilie os professores na motivação dos alunos sobre parte da história do munícipio, esta pesquisa apresenta um jogo sério desenvolvido em que o jogador vivencia a interação com os índios Xokleng no período entre 1897 e 1926, abrangendo entre a fundação do assentamento HansaHamônia até a demarcação das terras indígenas para a fundação do Posto Indígena Duque de Caxias. Entretanto, a colonização no Vale do Itajaí foi construída à sombra da violência, da dissimulação e do silêncio voluntário, com políticas de extermínio justificados pela periculosidade indígena (Kok \& Wittmann, 2007). O jogo, como um gênero de aventura, permite com que o aluno experiencie como protagonista desse movimento, entre o papel de caçador de índios até o papel do pacificador. O objetivo do jogo é fazer como que o aluno vivencie esses momentos para, mais tarde, o professor possa levar a discussão e reflexão à sala de aula.

Segundo Wassila e Tahar (2012) os jogos de aventura são baseados em um enredo em que o personagem sai em jornada para explorar mundo, recolher objetos, conversar com outros personagens do jogo e resolver enigmas. A narrativa fornece duas funções principais: motivação e estrutura cognitiva para solução de problemas (Dickey, 2006). Essa mecânica dos jogos de aventura, de se apropriarem de um personagem, permite que os alunos tenham um aprendizado significativo ao vivenciar as suas dificuldades, ou seja os problemas a serem solucionados, dentro de suas limitações da época, o que implica em tomar conhecimento dos fatos daquele momento.

Silva et al. (2017) apresentam um levantamento de 102 jogos para aprendizado de história no ensino médio. 45 jogos foram desenvolvidos especificamente para fins pedagógicos. Os demais são jogos de entretenimento que podem ser utilizados para a educação como séries conhecidas as de Age of Empires ou Assassin's Creed. Apenas 9 jogos retratam sobre a história do Brasil. Isso mostra uma grande lacuna para o desenvolvimento de jogos de história para assuntos específicos.

Este artigo está organizado da seguinte forma: a Seção 2 apresenta um resgate histórico sobre o período a ser tratado no jogo; a Seção 3 relata a metodologia utilizada nessa pesquisa para o seu desenvolvimento e a sua validação; a Seção 4 descreve o jogo desenvolvido; a Seção 5 apresenta a validação do jogo. Por fim, a Seção 6 apresenta as conclusões dessa pesquisa.

\section{Resumo Histórico da Colonização de Ibirama 1897-1926}

Uma expedição liberada por Albrecht Wilhelm Sellin através da Sociedade Colonizadora Hanseática, aportou na confluência com o Rio Itajaí do Norte, e no dia 8 de novembro de 1897 fundou a Colônia Hamônia (Wiese, 2007). Os primeiros imigrantes chegaram à Colônia em 1899, enfrentando dificuldades típicas do processo, como desentendimento entre colonos e a Sociedade Colonizadora, e os riscos de ataques dos índios da região (Bartel \& Pedruzi, 2018), batizados como Xokleng. Eles eram um povo nômade que viviam da caça, da coleta e dos saques aos colonos locais (Hoerhann, 2012).

Segundo Kok e Wittmann (2007), com o intuito de resolver os problemas com os indígenas da região, juntaram-se imigrantes, governos e agentes colonizadores e contrataram o serviço dos bugreiros, que eram caboclos que "caçavam" índios, pejorativamente conhecidos como bugres. Um dos protagonistas deste serviço contratado V. $18 \mathrm{~N}^{\mathrm{o}} 1$, julho, 2020 RENOTE DOI: 
era Martinho Marcelino de Jesus, mais conhecido como Martin Bugreiro, líder de um grupo responsável pelo extermínio de centenas de índios entre o final do século XIX e início do século XX.

Outro grupo indígena, de outras regiões, reconhecido na época eram os Kaingang que eram sedentários por possuírem conhecimentos rudimentares de agricultura, e por consequência facilitou a aproximação com os brancos (Hoerhann, 2012). Isso permitiu que eles foram utilizados como intérpretes com os Xokleng.

Em 1914, liderado por Eduardo de Lima e Silva Hoerhann, ocorreu o primeiro contato amistoso com os remanescentes Xokleng (Hoerhann, 2012). A ele foi lhe dado o objetivo de transformar os Xokleng em agricultores e restringi-los quanto a circulação às áreas a eles destinadas. Hoerhann ficou conhecido como "Pacificador dos Xokleng", recebendo deles a alcunha de "Katanghara", espécie de madeira muito rija, porém flexível, que era usada na confecção dos arcos.

Segundo Goulart (2000), em 1926 os Xokleng foram finalmente organizados em uma área reservada denominada Posto Indígena Reserva Duque de Caxias sob a administração de Hoerhann, com a promessa de que eles se sustentariam com o trabalho agrícola.

\section{Metodologia da Pesquisa}

Para o desenvolvimento dessa pesquisa contou-se com o apoio de um professor de história do Ensino Médio, que recomendou a lacuna a ser preenchida usando o jogo. $\mathrm{O}$ professor forneceu e indicou material bibliográfico sobre o período da história de Ibirama a ser abordado. Também já foram estabelecidas as turmas, o período e o protocolo de validação do jogo.

Em seguida, foram coletadas informações sobre o desenvolvimento de jogos sérios de história em relação às suas particularidades pedagógicas e estudados alguns jogos similares. Depois, houve um estudo técnico sobre o desenvolvimento de jogos quanto às ferramentas e métodos. Com base nessas informações, foi decidido desenvolver um jogo de aventura e definidos o enredo, os personagens, os desafios do jogo e a estética.

O jogo foi desenvolvido com Unreal Engine usando scripts em Blueprints. Os personagens foram criados com Adobe Fuse CC. O jogo desenvolvido passou por testes de usabilidade e garantia da qualidade pela equipe do Laboratório de Pesquisa e Desenvolvimento de Jogos Sérios e para Entretenimento (GameLab).

O protocolo de validação do jogo foi determinado da seguinte forma: como o professor lecionava para duas turmas do segundo ano Ensino Médio, uma delas foi eleita como Grupo Experimental (GE) e outra de Controle (GC). Ao GC foi lecionada uma aula sobre o assunto e na aula seguinte experimentaram o jogo. O GE usou o jogo primeiro para depois ter uma aula sobre o assunto. Em momentos distintos foram aplicados testes com 6 questões de múltipla escolha, que variavam sua ordem, tanto nas questões quanto nas respostas. Para o GC foram aplicados pré-teste antes da aula, e dois pós-testes: o primeiro após a aula e o segundo após o jogo. Para o GE foi aplicado um pré-teste antes do jogo e um pós-teste após o jogo. Além disso, os dois grupos responderam um inquérito com 49 itens baseado no EGameFlow (Fu et al., 2009) visando avaliar o jogo. Esse inquérito também tinha duas questões abertas: "O que não te agradou no jogo?" e "Deixe uma sugestão para melhoria ao jogo". Em ambos os grupos o tempo de jogo foi de 30 minutos.

\section{Hanse: Aventura na Colonização de Ibirama}

O jogo foi batizado como Hanse em homenagem à Sociedade Colonizadora Hansa e está disponível em Windows 64 bits para download em https://www.udesc.br/ceavi/ gamelab/tccs/eulergiachini. O jogo aborda o período desde o momento em que os 
exploradores aportaram em terras desconhecidas enfrentando índios perigosos até o momento da instalação do Posto Indígena Duque de Caxias. O jogo é no gênero aventura em terceira pessoa. Conforme o jogador vai avançando no enredo, ele assume outro personagem do período em que está vivendo. Foram definidos três personagens na seguinte ordem: Colono, Martin Bugreiro e Katanghara. O jogo foi organizado em duas fases: a primeira relacionada à época do encontro e extermínio dos índios, vivenciando os personagens Colono e Martin Bugreiro e a segunda com o objetivo de pacificação dos índios vivenciando Katanghara. As Figuras 1 e 2 apresentam duas telas do jogo descritas na Tabela 1 que apresenta cada fase dividida em quatro missões, onde cada missão possui tarefas fornecidas pelo jogo. Esteticamente o jogo foi desenvolvido com o modelo de baixos polígonos (low polygon $3 D$ ) que fornecem estruturas geométricas grosseiras, reduzindo significativamente o processamento de renderização (Chuah et al., 2014).

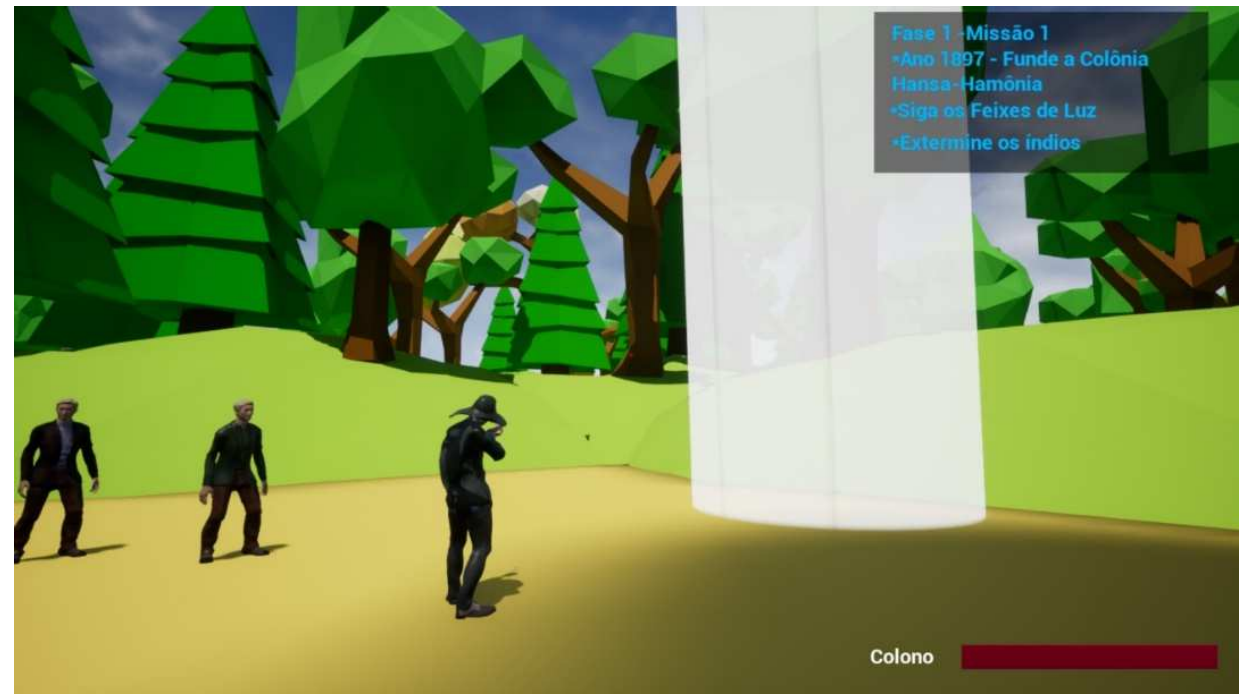

Figura 1 - Fase 1 Missão 1

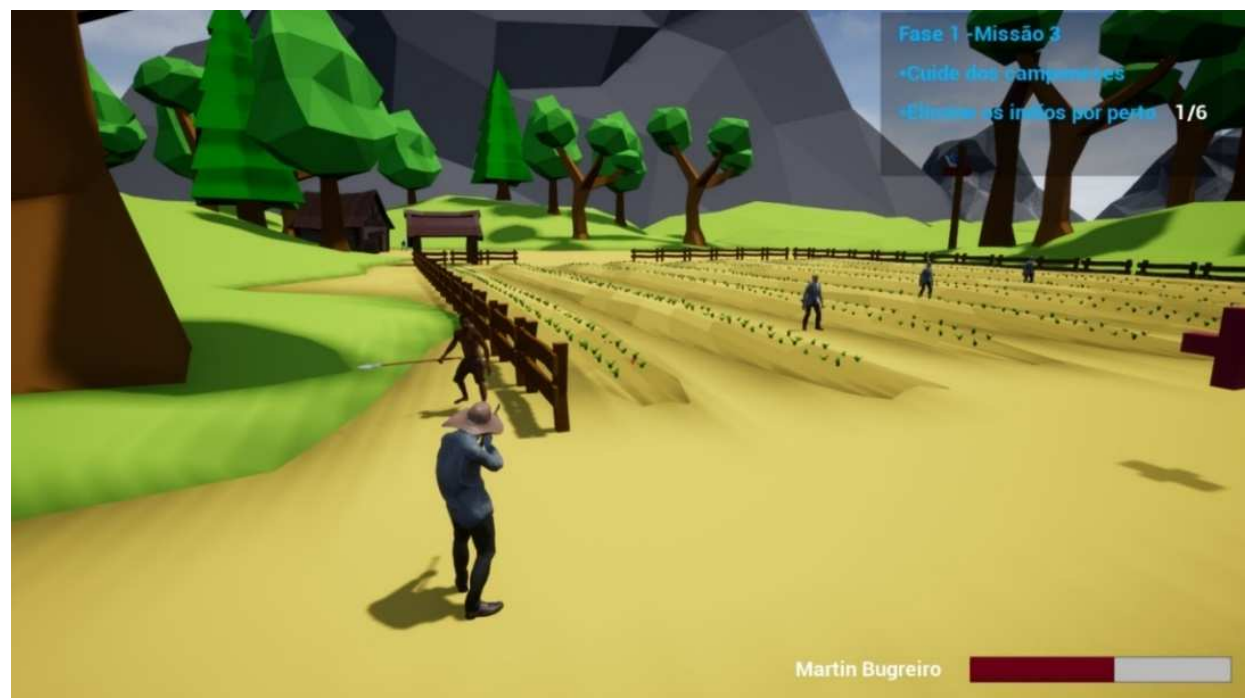

Figura 2 - Fase 1 Missão 2

Em ambas as figuras é possível observar no canto inferior direito o nome do personagem que o jogador está vivenciando e uma barra indicando a sua energia de vida. Caso os índios matem o personagem (zerem essa barra de energia), o jogador inicia sempre na mesma fase. Existem pontos no jogo para coletar e assim recarregar sua energia. Além de colocar o nome do personagem ao lado da barra de vida, outro artifício 
usado na aprendizagem é deixar explícita a data e os termos, seja nome do local ou do personagem a ser encontrado, junto dos objetivos da missão no canto superior direito. Com isso, o conteúdo a ser aprendido está integrado ao jogo sem interromper o fluxo da experiência correndo o risco do aluno perder o interesse no jogo (Chen, 2007).

Tabela 1 - Personagens, locais e tarefas no jogo

\begin{tabular}{|c|c|c|c|c|}
\hline Fase & Missão & Personagem & Local & Tarefas \\
\hline \multirow[t]{4}{*}{1} & 1 & Colono & Mata & $\begin{array}{l}\text { Quatro colonos } \mathrm{NPC}^{1} \text { seguindo o personagem do } \\
\text { jogador devem sobreviver ao final da missão. Juntos } \\
\text { irão desbravar as matas até encontrar o ponto para } \\
\text { fundar a Colônia. Os pontos a serem alcançados são } \\
\text { representados por feixes de luzes. O jogador vai } \\
\text { alcançando um por vez. Nas matas existem índios NPC } \\
\text { que, ao conseguirem enxergar os colonos acabam } \\
\text { correndo em direção do grupo e atacam com uma lança. } \\
\text { O colono está munido com uma espingarda e um facão, } \\
\text { útil nos confrontos diretos. Em todo o jogo não existe } \\
\text { restrição na quantidade de munição. Se o jogador quiser } \\
\text { evitar o confronto direto, deve sorrateiramente andar } \\
\text { pelas matas e atingir o índio antes que ele veja o grupo } \\
\text { (Figura 1). }\end{array}$ \\
\hline & 2 & \multirow{3}{*}{$\begin{array}{l}\text { Martin } \\
\text { Bugreiro }\end{array}$} & \multirow{3}{*}{$\begin{array}{l}\text { Fazenda } \\
\text { e mata }\end{array}$} & $\begin{array}{l}\text { Os índios estão saqueando as fazendas. Nessa missão, o } \\
\text { jogador precisa negociar com um camponês NPC (dono } \\
\text { da fazenda) para acertar o preço pelo serviço de } \\
\text { extermínio. A ação aqui é selecionar uma resposta em } \\
\text { cada diálogo, que deve conduzir ao sucesso da } \\
\text { negociação (Figura 2). }\end{array}$ \\
\hline & 3 & & & $\begin{array}{l}\text { Existem seis índios à espreita ao redor de uma plantação } \\
\text { sendo trabalhada pelos colonos NPC. O jogador precisa } \\
\text { matar esses índios. }\end{array}$ \\
\hline & 4 & & & $\begin{array}{l}\text { Após matar os índios ao redor da plantação, o jogador } \\
\text { precisa caçar mais } 8 \text { índios que estão na mata. }\end{array}$ \\
\hline \multirow{4}{*}{2} & 1 & \multirow{4}{*}{ Katanghara } & \multirow[t]{2}{*}{ Colônia } & $\begin{array}{l}\text { O jogador precisa negociar com o Diretor NPC da } \\
\text { Colônia para convencê-lo a dar permissão para iniciar o } \\
\text { processo de contato e pacificação com os Xokleng. A } \\
\text { tarefa aqui segue a mesma da Fase } 1 \text { missão } 2 \text { em que } \\
\text { precisa selecionar as respostas corretas conduzidas num } \\
\text { diálogo. }\end{array}$ \\
\hline & 2 & & & $\begin{array}{l}\text { O jogador precisa negociar com um índio Kaingang } \\
\text { NPC para que ele interceda junto aos Xokleng, } \\
\text { acompanhando-o na negociação. A tarefa é conduzir as } \\
\text { respostas corretas no diálogo. }\end{array}$ \\
\hline & 3 & & \multirow[t]{2}{*}{ Mata } & $\begin{array}{l}\text { O jogador precisa encontrar o cacique dos Xokleng } \\
\text { NPC, conta-lo sobre os planos da demarcação das terras } \\
\text { indígenas e convencê-lo a participar desse plano. A } \\
\text { tarefa é conduzir as respostas corretas no diálogo. }\end{array}$ \\
\hline & 4 & & & $\begin{array}{l}\text { O jogador deve encontrar os feixes de luz para } \\
\text { demarcação das terras e fundação do Posto Indígena } \\
\text { Duque de Caxias. }\end{array}$ \\
\hline
\end{tabular}

Como no jogo existem as tarefas de matar índios, seguindo os fatos históricos, a equipe de desenvolvimento tomou o cuidado em descaracterizar a violência: (1) esteticamente, através dos modelos de baixos polígonos, os rostos dos personagens são apenas silhuetas dos olhos e nariz; (2) não há sangue e nem vocalização quando acontece o ferimento ou a morte; (3) o índio desaparece após ser eliminado e o (4) ataque do índio é um movimento randômico com o braço que tem a lança.

${ }^{1}$ Non-player character (NPC): personagens controlados pelo jogo V. $18 \mathrm{~N}^{\mathrm{o}}$ 1, julho, 2020 


\section{Resultados da Validação}

A primeira hipótese a ser testada, em cada um dos dois grupos, é que os alunos não adquiriram conhecimento sobre o assunto tratado no jogo, ou seja,

$H_{0}: \mu_{\text {pré }}=\mu_{\text {pós-final }}$ - Não existe diferença significativa nas médias entre os testes antes e depois do jogo.

A segunda hipótese envolve a comparação entre os dois grupos, indicando que ambos tiveram o mesmo desempenho entre o pré-teste e pós-teste 1 . Sendo assim, para o GC será averiguado o desempenho com base no conhecimento obtido em aula, e para o GE, o conhecimento obtido com o jogo, ou seja,

\section{$H_{0}: \mu_{G C}=\mu_{G E}-$ Entre os grupos, não houve diferença significativa no desempenho dos pós-testes 1 .}

O GC tinha uma população de 19 alunos $(\mathrm{M}=17$ e $\mathrm{F}=2)$ e o $\mathrm{GE}$ de 16 alunos $(\mathrm{M}=10$ e $\mathrm{F}=6)$. $\mathrm{O}$ jogo foi experienciado individualmente cada um no seu computador do laboratório da escola. O interstício do GC entre as aulas e o jogo foi de 2 dias. A Tabela 2 apresenta os resultados dos testes de conhecimentos realizados com os grupos, lembrando que o teste possui 6 questões.

Tabela 2 - Estatística descritiva dos testes de conhecimento

\begin{tabular}{c|c|c|c|c|c|c}
\hline & Acertos/Total & Média & Mediana & $\begin{array}{c}\text { Desvio } \\
\text { padrão }\end{array}$ & Variância \\
\hline $\begin{array}{c}\text { Grupo de } \\
\text { Controle } \\
(\mathbf{n = 1 9 )}\end{array}$ & Pré-Teste & $83 / 114$ & 4,3684 & 5 & 1,2565 & 1,5789 \\
\hline $\begin{array}{c}\text { Grupo } \\
\text { Pós-Teste 1 }\end{array}$ & $82 / 114$ & 4,3157 & 4 & 1,1081 & 1,2280 \\
Póseste 2 & $100 / 114$ & 5,2631 & 6 & 1,1470 & 1,3157 \\
\hline (n=16) & Pré-Teste & $45 / 96$ & 2,8125 & 3 & 1,3768 & 1,8958 \\
\hline
\end{tabular}

Para avaliar a primeira hipótese com o GC, foi executado o teste ANOVA com medidas repetidas, pois envolve medir um mesmo sujeito duas ou mais vezes. O teste resultou em um $p$-valor $=0,006382$. Por consequência, com $99 \%$ de confiança pode-se rejeitar a hipótese nula de que os alunos do GC tiveram o mesmo desempenho entre os três testes, e que pelo menos um par de testes apresenta alguma diferença. Foi executado um teste de Tukey no intuito de averiguar qual(is) do(s) par(es) de testes possui(em) diferença(s) significativa(s). Conforme pode ser visto na Tabela 3, tanto o Pré-Teste quanto o Pós-Teste 1 tem diferenças significativas com o Pós-Teste 2 com 95\% de confiança. Com isso, a primeira hipótese é rejeitada para o $\mathrm{GC}$, apontando que os alunos tiveram melhor desempenho após o jogo. Para executar os testes foi utilizado o software Past (Hammer et al., 2001).

Para testar a primeira hipótese com o GE foi executado um teste t pareado. $\mathrm{O}$ resultado de $p$-valor $=0,0005$, rejeita a hipótese nula com $99 \%$ de confiança de que o desempenho foi o mesmo entre os testes do GE. Como a média do pós-teste foi maior do que o pré-teste, pode-se concluir que o desempenho foi melhor após o jogo também para o GE.

Tabela 3 - Resultados do Teste de Tukey sobre os testes do GC

\begin{tabular}{c|ccc}
\hline & Pré-teste & Pós-teste 1 & Pós-teste 2 \\
\hline Pré-teste & 0,9844 & $0,01827^{*}$ \\
Pós-teste 1 & 0,2388 & $0,01195^{*}$ \\
\hline \multicolumn{3}{c}{$* p<0,05$}
\end{tabular}

V. $18 \mathrm{~N}^{\mathrm{o}} 1$, julho, 2020

DOI: 
Para testar a segunda hipótese, será necessário construir um intervalo de confiança de $95 \%$ da diferença das médias para cada grupo, e então construir um gráfico com esses intervalos contra um eixo comum para verificar se existe uma intersecção (i.e. se existem alguns valores em comum). Se os intervalos não se sobrepõem, então com (pelo menos) 95\% de confiança pode-se afirmar de que as verdadeiras médias não são iguais. Para o GE, a diferença entre o pré-teste e o pós-teste 1 foi 1,8125 e o intervalo de confiança foi de 1,0195 até 2,6055. Para o GC, a diferença entre o pré-teste e o pós-teste 1 foi de $(0,0526)$ e o intervalo de confiança foi de $(0,8322)$ até 0,7269 . A Figura 3 apresenta ambos dois intervalos de confiança demonstrando que não existe intersecção entre eles. Assim, pode-se rejeitar a segunda hipótese nula de que ambos os grupos tiveram o mesmo desempenho independente na forma de aprenderem, e como a maior média foi do GE, pode-se concluir que o jogo foi mais eficiente para o aprendizado que as aulas.

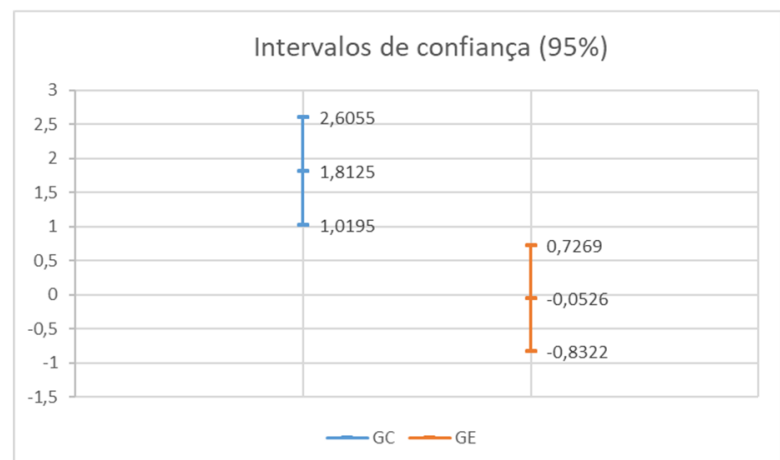

Figura 3 - Gráfico dos intervalos de confiança das médias dos testes dos grupos

Para finalizar os testes, foi aplicado o instrumento EGameFlow para avaliar a experiência de jogo. Ele possui 49 questões agrupadas em sete dimensões (concentração, clareza do objetivo, feedback, desafio, autonomia, imersão e melhoria do conhecimento) na escala likert com cinco níveis de concordância de discordo totalmente a concordo totalmente.

A escala likert é de natureza qualitativa ordinal, pois existe uma ordem natural entre os itens da escala (p.e., entre discordo totalmente e concordo totalmente). Para realizarem-se operações algébricas normalmente acaba-se transformando a escala em quantitativa discreta (neste caso, pontuando-a de 1 a 5). Quando isso é feito, admite-se incorretamente que existe uma relação linear entre os níveis de concordância. Neste contexto, Tastle, Russell e Wiermann (2008) propõem um novo índice para complementar a interpretação dos resultados obtidos a partir dos questionários. O nome deste índice é Consenso $(C n s(x))$, que utiliza a esperança matemática $(E(x))$ em sua equação, que pode ser interpretada como "o que se espera com mais e mais replicações dos questionários".

O $\operatorname{Cns}(x)$ deve ser interpretado como um percentual de concordância interna da distribuição no que diz respeito a $E(x)$. Como $0 \leq \operatorname{Cns}(x) \leq 1$, entende-se que, quanto mais próximo de 1 , mais os respondentes "concordam" com o valor esperado para a questão. Um conceito complementar ao Consenso é o de Divergência $(D v g(x))$ e esta é dada simplesmente por $1-\operatorname{Cns}(x)$. A Tabela 4 apresenta computadas a esperança matemática, índice de consenso e divergência das respostas dos 35 alunos.

Tabela 4 - Resultados da avaliação com o EGameFlow

\begin{tabular}{crrrrrrr}
\hline & $\begin{array}{c}\text { Concentra- } \\
\text { ção }\end{array}$ & $\begin{array}{c}\text { Clareza do } \\
\text { Objetivo }\end{array}$ & Feedback & Desafio & Autonomia & Imersão & $\begin{array}{c}\text { Melhoria do } \\
\text { conhecimento }\end{array}$ \\
\hline $\mathbf{E}(\mathbf{x})$ & 4,01 & 4,23 & 4,19 & 3,71 & 3,77 & 3,56 & 4,02 \\
Consenso & 0,78 & 0,78 & 0,69 & 0,59 & 0,65 & 0,63 & 0,73 \\
Divergência & 0,22 & 0,22 & 0,31 & 0,41 & 0,35 & 0,37 & 0,27 \\
\hline V. 18 $\mathrm{N}^{\mathbf{0}}$ 1, julho, 2020 & & & & & & RENOTE
\end{tabular}

DOI: 
Considerando numa escala de 1 a 5 , analisando os valores de cada uma das dimensões, pode-se afirmar que houve convergência (a grande maioria, acima de 70\%) em todas as dimensões com esperanças maiores que quatro (concordo). Aqui pode-se incluir também a dimensão de autonomia que, não atingiu o valor de concordo, mas esteve muito próximo. Vale ressaltar a dimensão Melhoria do Conhecimento que, conforme $\mathrm{Fu}$, Su e Yu (2009), o jogo deve aumentar o nível de conhecimento e habilidades do jogador enquanto cumpre a meta do currículo. Essa dimensão representa a aprendizagem percebida pelo aluno, ou seja, sua crença e sentimentos em relação a aprendizagem ocorrida (Caspi \& Blau, 2008) e reflete o senso do estudante que algum novo conhecimento foi adquirido e alguma nova compreensão foi alcançada, mesmo que esse conhecimento e compreensão subjetivos estiverem em contraste com o desempenho acadêmico (Caspi \& Blau, 2011). Como essa aprendizagem representa o grau de confiança que o aluno tem em relação ao seu domínio de um dado conhecimento, os alunos, mesmo não conhecendo os resultados finais dos seus testes, encerraram o experimento com a sensação de que adquiriram o conhecimento esperado.

Antes de comentar sobre as outras duas dimensões, a Figura 4 apresenta categorizada as respostas das questões abertas "o que não te agradou no jogo?" e "sugestões". Um dos alunos declarou na primeira pergunta "não ter habilidade para jogar". Como o aluno poderia dar mais de uma resposta, as quantidades são maiores do que os alunos. Pode-se observar que algumas categorias se repetem nas duas respostas, tanto porque alguns alunos repetiram a mesma resposta nas duas questões, quanto alguns classificaram uma resposta como sugestão e outros como algo que não agradou. Os erros de funcionamento no jogo se referem, por exemplo, em relação aos comportamentos e interações com os NPCs.

A dimensão de desafio corresponde à oferta de desafios adequados ao nível de habilidades do jogador, onde a dificuldade desses desafios deve mudar de acordo com o aumento no nível de habilidade do jogador, ocorreu a mais baixa concordância (59\%). Complementando, a imersão foi a dimensão com menor esperança matemática, ainda que não foi consenso da grande maioria, mas por boa parte deles $(63 \%)$ concordam com esse valor.

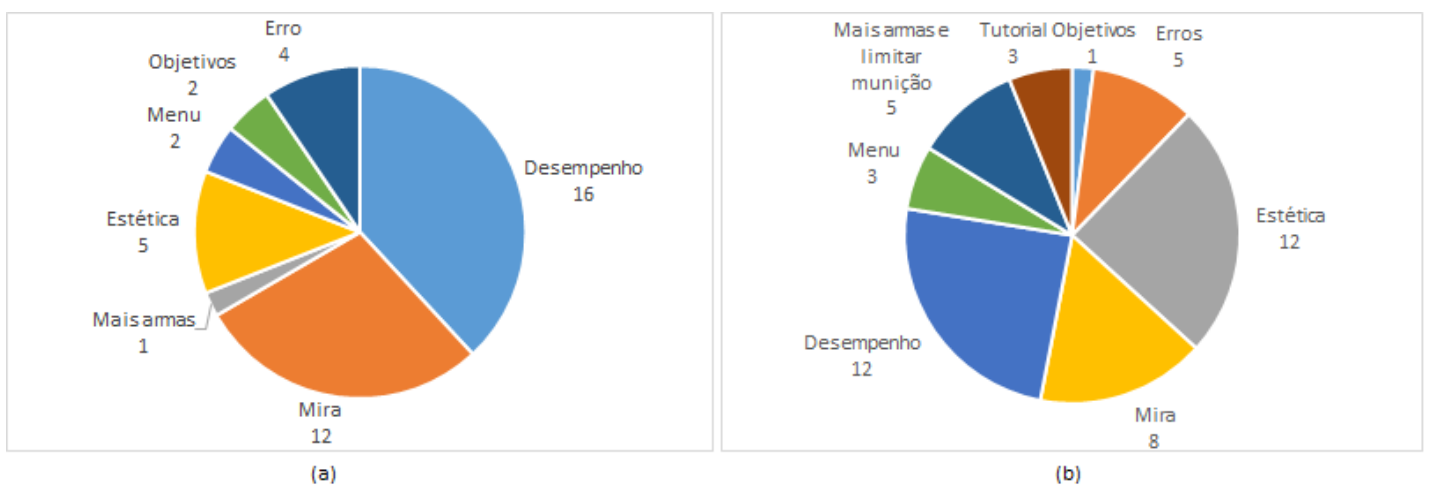

Figura 4 - Respostas categorizadas (a) O que não te agradou? (b) Sugestões.

Pode-se buscar uma justificativa desses valores de concordância analisando a Figura 4. Somando as duas respostas, em torno de $31 \%$ das respostas dificuldades ou sugeriu que o desempenho melhorasse. Os alunos sentiram problemas de renderização no jogo devido às configurações dos equipamentos da escola. $O$ jogo não tinha sido testado anteriormente nas configurações do laboratório onde os alunos usaram. Esse problema de desempenho dificulta o jogador imergir no jogo, até porque ele se irrita com o próprio jogo. Em relação à mira, e por essa razão a munição foi determinada infinita, ela foi projetada para ser falha, pois era uma espingarda do final do século XIX. Porém, como V. $18 \mathrm{~N}^{\mathrm{o}} 1$, julho, 2020 RENOTE DOI: 
no jogo isso nunca foi mencionado, os alunos acabaram por perceber o problema e classificá-lo como um erro ou algo a ser melhorado. Percebe-se que muitas sugestões, e problemas, são descritas devido à experiência anterior desses alunos com jogos de tiro em terceira pessoa. Tanto que na estética (em torno de 19\% de todas as respostas) referiam-se à variabilidade de cenários, NPCs e animações, e também quanto ao estilo low poly.

\section{Conclusões}

Esse artigo apresentou um jogo de aventura para ser usado nas aulas de história do município de Ibirama, permitindo que o aluno vivencie as três primeiras décadas de sua colonização. Duas turmas foram usadas para testar o jogo. Em uma das turmas foi lecionado o assunto anteriormente à sessão do jogo. Através dos testes (pré e pós) de conhecimento aplicados, pôde-se concluir com significância estatística (primeira hipótese) que ambas as turmas tiveram evolução no desempenho dos testes. Ao comparar o desempenho resultante das aulas lecionadas e da turma que só jogou, ainda foi possível concluir que essa última apresentou um desempenho maior que a anterior. Não é intenção da pesquisa nem questionar e sequer avaliar a didática do professor, mas existem evidências estatísticas (segunda hipótese) de que jogando os alunos alcançaram uma maior proficiência no assunto, e no mesmo tempo da aula.

Como o objetivo principal da disciplina de história não é decorar uma lista de datas e fatos, mas praticar a discussão e reflexão sobre os fatos ocorridos, para entender a situação atual e não se repetir os mesmos erros. Porém, os professores somente alcançam o nível apropriado de discussão, se os alunos efetivamente têm o conhecimento sobre os fatos que se desejam refletir. Com a abordagem de uso de jogos apresentada nesse artigo, os alunos significativamente aprendem datas, vultos e fatos com toda a atenção deles, e o professor ganha tempo e eficiência no que mais importa na disciplina de história que é o aprendizado de mais alto nível.

Nenhum jogo serve para TODAS as pessoas. Porém, através da avaliação da experiência de jogo, a grande maioria apresentou satisfação com o jogo. Existem pontos a melhorar (como pode ser observado na Figura 4), mas através da análise das hipóteses, pode-se concluir que ele pode ser utilizado por outros professores, ou servir de inspiração para novos jogos.

\section{Referências}

Andrade, D. E.-J. (2007). O lúdico e o sério: experiéncias com jogos no ensino de história. História \& Ensino, 13, 91-106.

Bartel, C. E., \& Pedruzi, T. (2018). Descaminhos da História : Ressignificações Identitárias em Ibirama/SC. In Anais do XVII Encontro Estadual de História da ANPUH-SC. Joinville.

Caimi, F. E. (2006). Por que os alunos ( não ) aprendem História ? Reflexões sobre ensino , aprendizagem e formação de professores de História. Tempo, 11(21), 17-32.

Caspi, A., \& Blau, I. (2008). Social presence in online discussion groups: Testing three conceptions and their relations to perceived learning. Social Psychology of Education, 11(3), 323-346.

Caspi, A., \& Blau, I. (2011). Collaboration and psychological ownership: How does the tension between the two influence perceived learning? Social Psychology of Education, 14(2), 283-298.

Chen, J. (2007). Flow in games (and everything else). Communications of the ACM, 
$50(4), 31$.

Chuah, S.-P., Yuen, C., \& Cheung, N.-M. (2014). Cloud gaming: a green solution to massive multiplayer online games. IEEE Wireless Communications, 21(4), 78-87.

Dickey, M. D. (2006). Game Design Narrative for Learning: Appropriating Adventure Game Design Narrative Devices and Techniques for the Design of Interactive Learning Environments. Educational Technology Research and Development, 54(3), 245-263.

Fu, F. L., Su, R. C., \& Yu, S. C. (2009). EGameFlow: A scale to measure learners' enjoyment of e-learning games. Computers and Education, 52(1), 101-112.

Gee, J. P. (2003). What video games have to teach us about learning and literacy. New York: Palgrave Macmillan.

Goulart, M. do C. R. K. (2000). Vale dos Índios - Vale dos Imigrantes. Blumenau: Cultura Em Movimento.

Hammer, Ø., Harper, D. A. T., \& Ryan, P. D. (2001). PAST : Paleontological Statistics Software Package for Education and Data Analysis. Palaeontologia Electronica, $4(1)$.

Hoerhann, R. C. de L. e S. (2012). O Serviço de Proteção aos Índios e a Desintegração Cultural dos Xokleng (1927 - 1954). Tese de doutoramento em Tese (doutorado), Universidade Federal de Santa Catarina.

Kok, G., \& Wittmann, L. T. (2007). O vapor e o botoque: imigrantes alemães e índios Xokleng no Vale do Itajaí/SC. Florianópolis: Letras contemporâneas.

McCall, J. (2016). Teaching History With Digital Historical Games : An Introduction to the Field and Best Practices. Simulation \& Gaming, 47(4), 517-542.

Pereira, N. M., \& Giacomoni, M. P. (2018). Flertando com o Caos : os jogos no Ensino de História. In Jogos e ensino de história (pp. 9-18). Porto Alegre: Editora da UFRGS.

Seffner, F. (2018). Aprender e ensinar história: como jogar com isso? In Jogos e ensino de história (pp. 19-34). Porto Alegre: Editora da UFRGS.

Silva, M. A. da, \& Fonseca, S. G. (2010). Ensino de História hoje : errâncias , conquistas e perdas. Revista Brasileira de História, 31(60), 13-33.

Silva, L. S. e, Bezerra, D. de F., Elias, A. T., \& Silva, A. J. (2017). Aprendizagem mediada por jogos eletrônicos em História do ensino médio: uma revisão sistemática. Nuevas Ideas En Informática Educativa, 13, 343-348.

Tastle, W. J., Russell, J., \& Wiermann, M. J. (2008). A new measure to analyze student performance using the Likert scale. Information Systems Education Journal, 6(35), $1-7$.

Wassila, D., \& Tahar, B. (2012). Using serious game to simplify algorithm learning. In International Conference on Education and e-Learning Innovations (pp. 1-5). Sousse, Tunisia.

Wiese, H. (2007). Terra da fartura: história da colonização de Ibirama. Ibirama: Edigrave. 